\title{
Neural responses associated with cue evoked emotional states and heroin in opiate addicts
}

\author{
L.A. Sell ${ }^{\text {a,*, J.S. Morris }}{ }^{\text {b }}$ J. Bearn ${ }^{a}$, R.S.J. Frackowiak ${ }^{b}$, K.J. Friston ${ }^{b}$, \\ R.J. Dolan ${ }^{b}$ \\ ${ }^{a}$ National Addiction Centre, Institute of Psychiatry, 4 Windsor Walk, London SE5 8AF, UK \\ ${ }^{\mathrm{b}}$ Wellcome Department of Cognitive Neurology, Institute of Neurology, London WC1N 3BG, UK
}

Received 18 May 1999; accepted 14 December 1999

\begin{abstract}
Ten male opiate addicts, who were current heroin injectors, underwent positron emission tomographic (PET) scanning during exposure to a sequence of six alternating drug related and neutral video cues, on two occasions. After the second scan, each subject received heroin or placebo using a randomised single-blind procedure. This design allowed the investigation of patterns of brain activity during a range of self-reported cue evoked emotional states, both in the presence and absence of heroin. Self-reports of 'urge to use' correlated strongly with increased regional blood flow ( $\mathrm{rCBF}$ ) in the inferior frontal and orbitofrontal cortex target regions of the mesolimbic dopaminergic system, implicated in conditioning and reward. 'Urge to use' was also associated with highly significant increased $\mathrm{rCBF}$ in the right pre-cuneus, an area associated with episodic memory retrieval, and in the left insula, implicated in the processing of the emotional components of stimuli. Self-reports of feeling 'high' correlated with rCBF activation in the hippocampus, an area relevant to the acquisition of stimulus-associated reinforcement. (C) 2000 Elsevier Science Ireland Ltd. All rights reserved.
\end{abstract}

Keywords: Opiate dependence; Heroin; Cue; Neuroimaging

\section{Introduction}

Drugs with potential for abuse and dependence activate reward pathways in animals (Altman et al., 1996). Substances which activate these systems directly can be considered unconditioned stimuli (UCS) and act as primary reinforcers. Stimuli which are repeatedly associated with UCS, become conditioned stimuli (CS), acquiring secondary reinforcing properties (Davis and Smith, 1976; Childress et al., 1986a). As a drug user becomes dependent on a drug and maintains a drug-using lifestyle, he or she will carry out repeated patterns of drug-using behaviour, using certain objects and visiting certain environments. In this way contexts associated with drug use such as drug paraphernalia and locations where the drug is bought and used can act as a CS (Childress et al., 1993).

\footnotetext{
* Corresponding author. Present address: Drugs North West, Mental Health Services of Salford, Bury New Road, Manchester M25 3BL, UK. Tel.: + 44-161-7739121; fax: + 44-161-7723595.
}

Fifty years ago, Wikler (1948) described the responses of human addicts to environmental stimuli previously associated with heroin use. Addicts dependent on heroin but abstinent, often following incarceration, have provided graphic accounts of the powerful effects of re-entering specific neighbourhoods. They describe specific symptoms of opiate withdrawal and experience a strong desire to re-instate drug use. This phenomenon has been studied systematically in patients addicted to opiates, cocaine and alcohol, using a range of drug-related and neutral cues (Childress et al., 1986a,b, 1993). Drug-related cues have included watching videos of drug use, listening to scripts about drug use and handling drug-related paraphernalia, such as needles, syringes, spoons, cigarette filters and aluminium foil. In these circumstances, addicts demonstrate physiological and subjective self-report evidence of drug-like, opponent process and withdrawal-like effects. There may be little difference in practice between the last two. Heroin-like effects include feeling high and constricted pupils, while withdrawal-like effects include 
dysphoria, dilated pupils, anxiety and tachycardia. Opponent process theory describes stimulus anticipatory behaviour, which represents adaptational responses to ensure stimulus-induced changes do not perturb an organism's homeostasis (Solomon and Corbit, 1974). According to this theory, the presence of a conditioned stimulus may result in counteractive physiological changes, which minimise the effects of the event predicted by the CS. Thus an organism's tolerance to a drug may occur in a particular environment and may be reduced or absent in others (Robbins and Ehrman, 1992). Conditioned opponent process effects to heroin include dysphoria, dilated pupils, anxiety and tachycardia, which coincide with opiate withdrawal symptoms.

In addition to physiological recording in cue exposure paradigms, self-reported urge to use the drug has been measured. A strong urge to use the drug in response to exposure to cues associated with previous drug use has been termed 'conditioned craving' (Childress et al., 1986b). It may be associated with conditioned drug-like, drug-opposite or opponent process effects. Conditioned effects in general may also be associated with a generalised state of arousal, and the distinction between cue specific and generalised arousal effects are unclear (Robbins and Ehrman, 1992). Indeed the meaning and utility of the term craving is not clearly described or agreed in the literature (Pickens and Johanson, 1992). Another commonly used term is an urge to use a drug. According to one model an urge to use drugs arises from the interruption of an automatic process (Tiffany, 1990). In this paper usage of the term urge to use heroin is a composite self-report measure.

Animal data show that heroin activates the ascending mesolimbic dopamine pathways, which mediate reward, and this activity is critical to its primary reinforcing properties (Wise and Bozarth, 1987; Wise, 1988). Heroin disinhibits gamma amino-butyric acid (GABA) interneurons in the ventral tegmental area (VTA) of the midbrain. This results in increased firing of VTA dopaminergic neurons and release of dopamine in the nucleus accumbens and orbitofrontal cortex, so that the mesolimbic dopamine system is activated (DiChiara and North, 1992; Wise, 1996). Target areas of the VTA dopaminergic activation also include other areas of the ventral striatum, pre-frontal and cingulate cortex (Kim et al., 1986; Wise and Bozarth, 1987; Schulteis and Koob, 1994; DiChiara, 1995; Altman et al., 1996; Sell et al., 1999).

Activation of the dopaminergic systems is also implicated in exposure to cues (secondary reinforcement) in animals with increased firing of VTA dopaminergic neurons in response to exposure to stimuli previously associated with drugs (Schultz et al., 1997). Drug-related cue exposure has also been shown to potentiate the release of dopamine in the nucleus accumbens
(Fontana et al., 1993), mirroring increased dopamine release in the nucleus accumbens in response to cues predicting other rewards, namely ingestive and sexual reward (Phillips et al., 1991). Salient drug-related cues modulate cerebral activity in target areas of the ascending dopamine system in animals (Trusk and Stein, 1988). These systems may influence human drug-seeking behaviour since haloperidol reduces cue-evoked cocaine craving in humans (Berger et al., 1996).

Whilst the role of the mesolimbic dopamine pathways in reward is critical, it is not exclusive. Interactions between neuromodulatory dopaminergic systems ascending from the brain stem, and target limbic regions have an important role (Robbins et al., 1989; Robbins and Everitt, 1996). The meso-amygdaloid system is critical to the acquisition of salience by opiate-related cues due to its role in the formation of associations between UCS and CS (Cador et al., 1989; Williams et al., 1993; Whitelaw et al., 1996). Although the neurotransmitter most studied to date is dopamine, it is not exclusively responsible (Koob, 1992) and other putative important neurotransmitters are serotonin, gamma amino butyric acid and glutamate. In summary, animal data demonstrate that a network of dopaminergic systems embracing the mesolimbic dopamine system, the mesoamygdaloid system, limbic and paralimbic circuitry, orbitofrontal and ventromedial prefrontal cortical structures are all implicated in the conditioning processes.

Data from both animal studies and the human studies described earlier in this section have informed theories of human response to drugs of abuse themselves (UCS) and to cues associated with the drugs (CS). However, the daily life of a drug addict involves a complex pattern of exposure to both UCS and CS. The ability to test the findings derived from animal studies in the human addictive state has recently been demonstrated. We have used PET scanning to investigate the impact of heroin administration and exposure to heroin related cues, on neural activity in addicted patients. We noted activation of midbrain structures by both heroin and heroin-related cues, and the modulation of the response of cingulate and basal forebrain regions to heroin-related cues by ascending midbrain systems (Sell et al., 1999). We present here data from the same study where the emphasis is on changes in neural activity, indexed by regional cerebral flow (rCBF), associated with subjective reports. Our previous report indicated that the salient video induced a significant urge to use heroin. Our central hypothesis is that the urge to use heroin correlates with cerebral activation in the neural system subserving conditioning processes and reward. In view of the wide range of subjective measures acquired, we were also in the position to assess their relationship, for example mood and anxiety, to cerebral activity. 


\section{Method}

\subsection{Subjects}

Subjects were ten male in-patients at the detoxification unit of the Bethlem Hospital. All subjects underwent a detailed drug, alcohol and psychiatric history including corroboration of recent drug use by visual inspection of sites of injection and by urinalysis. All were current heroin injectors over 18 years of age, and gave informed consent to the procedure, which was approved by the local hospital ethics committee. Serious psychiatric or medical illness, alcohol dependence in the last two years, or a history of cocaine or amphetamine dependence, resulted in exclusion. Mean age was 31.6 years (range 23-39). All were white Caucasian. Mean length of heroin use was 12.4 years (range 2-19), of dependence 8.7 years (range 2-16) and of injecting drugs 9.5 years (range $1-18$ ). They had a mean of 2.8 previous in-patient de-toxifications (range $0-5$ ). A total of eight received a prescription for methadone prior to admission; mean daily dose $28.75 \mathrm{mg}$ (range 15-50). All used heroin and two used illicit methadone. Total daily methadone equivalent dose, taking account of prescribed and illicit methadone and heroin, was $54 \mathrm{mg}$ [range 27-110]; assuming $1 \mathrm{~g}$ street heroin $=60 \mathrm{mg}$ methadone. Subjects injected a mean of 2.89 times daily (range 1-6). A total of seven currently used diazepam, one on a daily basis. Mean weekly dose, including prescribed and illicit sources, of those who used diazepam was $213 \mathrm{mg}$ (range 37.5-750). All had drunk alcohol, and three did so currently. All had used cannabis, of whom five still did. All had used amphetamine but none did so currently. A total of eight subjects had used cocaine, of whom seven still did on rare occasions. A total of seven had used LSD and seven ecstasy; neither drug was currently used by any subject. No subject used; barbiturates, although four had in the past; solvents, although three had in the past; or other opiates, although three had in the past.
Subjects underwent methadone dose titration, and stabilisation using single blind methadone administration took place on days one and two following admission to hospital. Four subjects co-dependent on benzodiazepines were also stabilised on diazepam.

\subsection{Scanning procedure}

Subjects had a Magnetic Resonance Scan on Day 3. PET scans were performed on days 3 and 5 according to the design shown in Table 1 , counterbalancing for order of placebo and heroin. At 8.30 on scanning days, subjects were given $50 \%$ of the total methadone dose they had consumed during the previous $24 \mathrm{~h}$. Diazepam was maintained at a constant dose for the duration of the study. During PET data acquisition, subjects viewed alternately a colour video of a volunteer assembling a household table lamp (neutral video) and a colour video showing a different volunteer preparing and administering heroin by injection (salient video). Cues in the heroin-salient video included a tourniquet, vitamin $\mathrm{C}$ container, Coke can, spoon, candle, syringe, needles, simulated heroin wrap and brown powder, loaded syringe and images of heroin preparation using these items, followed by images of injecting by the same individual. Each video lasted $5 \mathrm{~min}$ and PET data acquisition started during the final $40 \mathrm{~s}$ of the video. Scans of the distribution of $\mathrm{H}_{2}^{15} \mathrm{O}$ were obtained using a Siemens/CPS ECAT EXACT HR + PET Scanner operated in high sensitivity 3 -D mode. Subjects received a total of $350 \mathrm{Mbq}$ of $\mathrm{H}_{2}^{15} \mathrm{O}$ over $20 \mathrm{~s}$ through a forearm cannula for each of the 12 scans. Integrated activity was measured over a 90 s time window. The PET images comprised i, j, and $\mathrm{k}$ voxels $(2 \times 2 \times 3 \mathrm{~mm})$ with a $6.4 \mathrm{~mm}$ transaxial and $5.7 \mathrm{~mm}$ axial resolution (full width at half maximum).

\subsection{Subjective ratings}

'Ratings' data were gathered during the $3 \mathrm{~min}$, which elapsed between each video, according to the

Table 1

Study design ${ }^{\mathrm{a}}$

\begin{tabular}{|c|c|c|c|c|c|c|}
\hline Scans & 1 & 2 & 3 & 4 & 5 & 6 \\
\hline \multicolumn{7}{|l|}{ Day A } \\
\hline Video condition & Neutral & Salient & Neutral & Salient & Neutral & Salient \\
\hline \multicolumn{7}{|l|}{ Day B } \\
\hline Video condition & Neutral & Drug & Neutral & Drug & Neutral & Drug \\
\hline
\end{tabular}

\footnotetext{
a Subjects underwent six scans on each day, watching a video during each scan, and on each day receiving a single injection of heroin or placebo after the second scan and ratings. Therefore scans 3-6 are designated as placebo or heroin condition. Visual analogue scales ('ratings') were measured at baseline and immediately after each scan. Results of these are in Figs. 1 and 2. Order of days A and B was counterbalanced.
} 


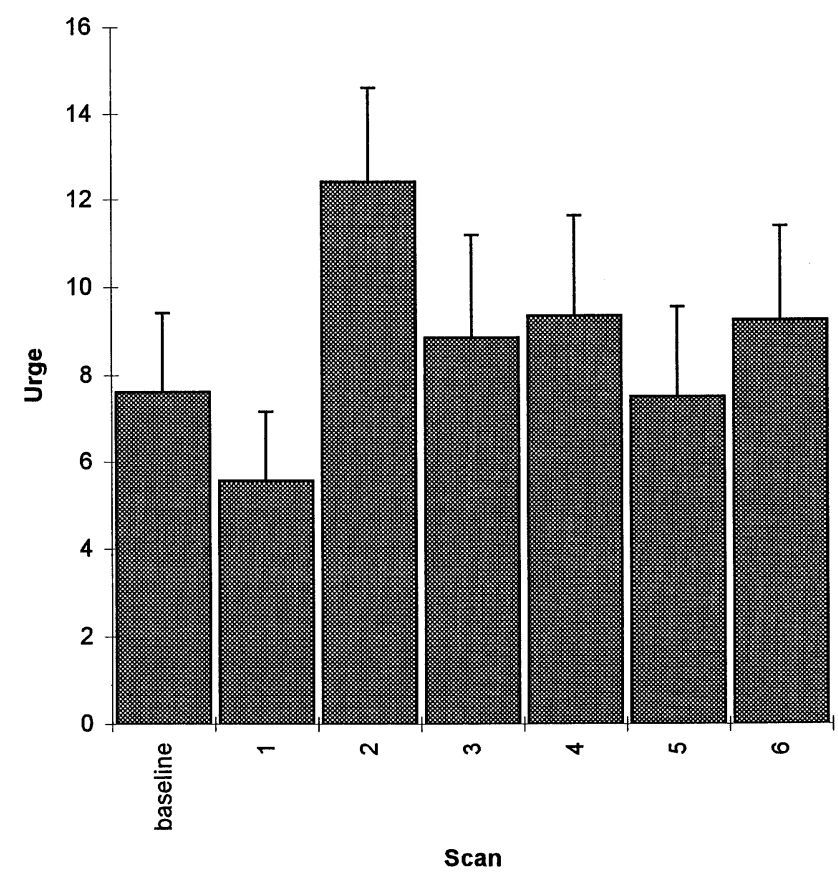

Fig. 1. Subjective composite urge to use heroin at baseline and after each scan.

cyclotron activity cycle. The ratings were subjective measures using verbal analogue scales (VAS) (1-10) of; craving for heroin [VAS — 'craving'], desire for a hit [VAS - 'hitdesire'], desire to leave and score [VAS 'hitdrive'], feeling high [VAS — 'high'], withdrawal symptoms [VAS — 'with'], feeling happy [VAS 'happy'], feeling tense, [VAS — 'tense']. The ratings were obtained by demonstrating a scale of 1-10 and then asking subjects to report how they felt using the scale in response to sets of opposite statements (Sell et al., 1995). Pulse and blood pressure were also measured. All measures were done at baseline and after each scan, in order to calculate a change from baseline for each scan. A composite measurement 'urge to use' was calculated by summing the change from baseline responses to the VASs 'craving', 'hitdesire' and 'hitdrive', giving a possible maximum 'urge' rating of 30 .

\subsection{Drugs}

Each subject was given placebo (normal saline) or 20 $\mathrm{mg}$ heroin (Diamorphine hydrochloride, Medeva Pharma Ltd.) after the second scan and video. Subject and scanning staff were kept strictly blind to the condition. The only person who knew was the administering doctor who prepared and gave a single intravenous bolus, following the same procedure and using the same words on each occasion. Thus the subject knew they were receiving an injection but were reminded that it could be placebo or heroin each time.

\subsection{Statistical analysis}

The data were analysed with Statistical Parametric Mapping (SPM96, Wellcome Department of Cognitive Neurology, London) implemented in Matlab (Mathworks, Sherborn, MA).SPM uses the general linear model and the theory of Gaussian fields to interpret functional imaging data in a number of ways. It enables the multiple datasets generated by the scanning process to provide estimates of regional cerebral blood flow $(\mathrm{rCBF})$ in the experimental conditions applied. The general methods employed by SPM are described in detail by Friston et al. (1995a). Structural MRIs from each subject were co-registered to the PET data following realignment of the PET time series. All the scans were then transformed into a standard stereotactic space (Friston et al., 1995b; Talairach and Tournoux, 1988). The scans were smoothed using a Gaussian filter set at $12 \mathrm{~mm}$ full width at half maximum. The rCBF measurements were adjusted to a global mean of 50 $\mathrm{ml} / \mathrm{dl}$ per min. A blocked (by subject) ANCOVA model was fitted to the data at each voxel, with subjective rating 'urge to use heroin' as a covariate of interest and global $\mathrm{CBF}$ as a confounding covariate (Friston et al., 1991).

The self reported ratings and physiological measurements were analysed using repeated measures analysis of variance and post hoc $t$-tests, where the repeated measures analysis of variance indicated main effect of interactions, which were judged statistically significant, having a $P$ value less than or equal to 0.05 .

\section{Results}

Figure 1 shows the self-reported effects of the urge to use heroin. There was a significant effect of the salient visual cue (video) on the composite rating of reported urge to use heroin $(F=14.11, \operatorname{df}(1,8), P<0.01)$. There was an effect of session order on urge to use $(F=6.34$, $\operatorname{df}(1,8), P<0.05)$, however this did not influence the effect of the video cue. The effect of the video cue was influenced by time (Interaction; $F=14.18, \operatorname{df}(2,16)$, $P<0.01$ ); Fig. 1 and post hoc $t$-tests indicate that the effect of the cue was greatest in the initial contrast, i.e. first neutral with first salient video (means 5.65, 12.40, $t=-5.79$, df $19, P<0.001)$ than in subsequent contrasts, i.e. second neutral with second salient video (means 8.85, 9.35, $t=-0.033$, df 19, $P=\mathrm{NS}$ ) and third neutral with third drug video(means $7.50,9.25$, $t=-2.67$, df $19, P<0.05$ ).

Fig. 2 shows the self-reported effect of feeling high. There was an effect of heroin on the report of feeling high $[F=12.65, \operatorname{df}(1,8), P<0.01]$, an effect of time $[F=16.31, \operatorname{df}(2,16), P<0.01]$, and the effect of time influenced the effect of the drug [Interaction; $F=8.04$, 


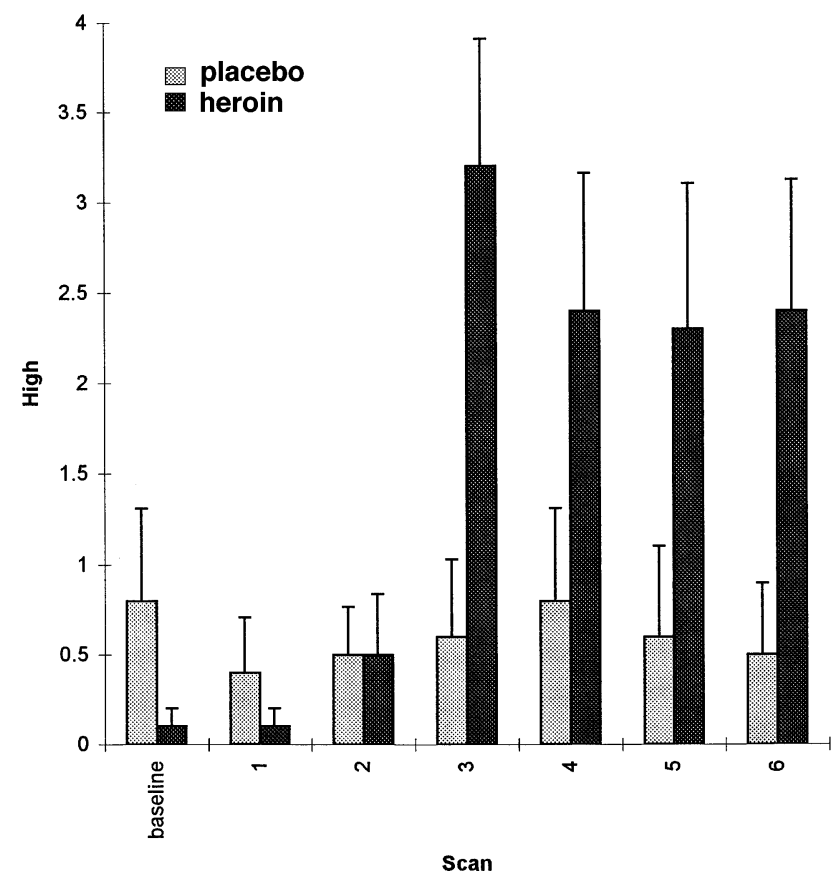

Fig. 2. Subjective report of feeling high at baseline, and after each scan during placebo and heroin sessions. Pale grey, placebo; dark grey, heroin sessions.

$\operatorname{df}(2,16) P<0.01]$. There was no effect of the salient video on the report of feeling high. There was no significant main effect of either heroin or salient video on the subjects' self report of symptoms of withdrawal. There was an effect of the salient video influenced by session order (placebo or heroin session first) on withdrawal (Interaction: $F=5.41, \operatorname{df}(1,8), P<0.05)$. There was an increase in withdrawal during the salient video in session order 1.

The self-report of feeling happy was influenced by an interaction of session order by drug by video by time
(Interaction; $F=4.48, \operatorname{df}(2,16), P<0.05)$. An increase in ratings of 'happy' in during the salient video was enhanced by heroin in session order 2. There was no interaction or effects on the self report of feeling tense. There was an effect on pulse of time $(F=4.04, \operatorname{df}(2,16)$, $P<0.05)$ but no significant effects or interactions on blood pressure. Pulse rate gradually decreased during the course of the experiment.

Neuroimaging results are reported for data where the level of significance survives correction for multiple comparisons for the entire brain volume $(P<0.05$, corrected) where there was no a priori prediction, and uncorrected where specific predictions were made. The condition contrasts are described in our previous publication (Sell et al., 1999). Both heroin and the salient video were associated with significant increases in midbrain cerebral flow. Brain regions where cerebral blood flow covaries with reported urge to use heroin are shown in Table 2 and Fig. 3. Urge to use heroin was significantly correlated with changes in $\mathrm{rCBF}$ in prefrontal cortex, specifically in inferior frontal cortex and orbitofrontal cortex. An unpredicted finding, which remained highly significant following correction for multiple comparisons, was a strong positive correlation with a posterior cingulate region corresponding with the right pre-cuneus. A further unpredicted finding was a significant correlation between urge and bilateral reductions in neural response in the occipital cortex.

Table 3 and Fig. 4 show the areas where rCBF correlated with the self report of feeling high. A neural response in bilateral anterior hippocampus correlated significantly with self report of feeling high. $(P<0.01$, uncorrected). There was no area of significant deactivation. rCBF correlations with the other cue evoked emotional states, feeling happy, tense and experience of withdrawal, together with pulse rate are shown in Table 3.

Table 2

Stereotactic coordinates and statistical magnitude of brain areas in the analysis using composite urge to use heroin as the covariate of interest.

\begin{tabular}{|c|c|c|c|c|c|c|c|}
\hline Region & Brodmann area & Hemisphere & $x$ & $y$ & $z$ & $Z$ score & $P$ value \\
\hline \multicolumn{8}{|l|}{ Areas of increased activation } \\
\hline Pre-cuneus (posterior cingulate cortex) & 7 & $\mathrm{R}$ & 0 & -38 & 44 & 4.65 & $<0.05^{\mathrm{a}}$ \\
\hline Inferior frontal cortex & 47 & $\mathrm{~L}$ & -30 & 16 & -16 & 4.12 & $<0.001^{\mathrm{b}}$ \\
\hline Inferior frontal cortex & 47 & $\mathrm{~L}$ & 40 & 20 & -14 & 3.44 & $<0.001^{\mathrm{b}}$ \\
\hline Orbital frontal cortex & 11 & $\mathrm{R}$ & 6 & 14 & -22 & 4.06 & $<0.001^{\mathrm{b}}$ \\
\hline \multicolumn{8}{|l|}{ Areas of decreased activation } \\
\hline Occipital cortex & 19 & $\mathrm{R}$ & 28 & -66 & 20 & 4.51 & $0.05^{\mathrm{a}}$ \\
\hline Occipital cortex & 19 & $\mathrm{~L}$ & -30 & -70 & 6 & 3.70 & $>0.05$ \\
\hline
\end{tabular}

\footnotetext{
${ }^{\text {a }} P$ corrected for whole brain comparison.
}

${ }^{\mathrm{b}} P$ uncorrected. 


\section{sagittal}

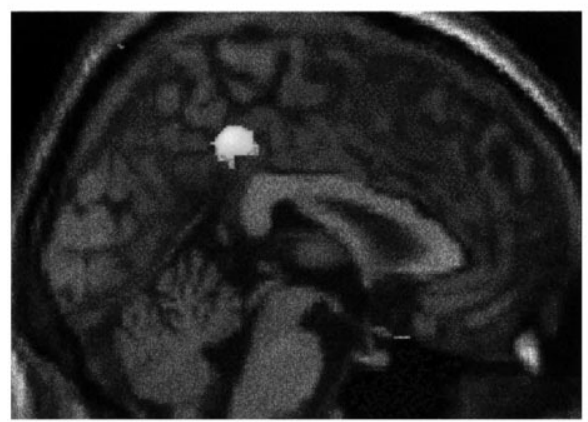

transverse

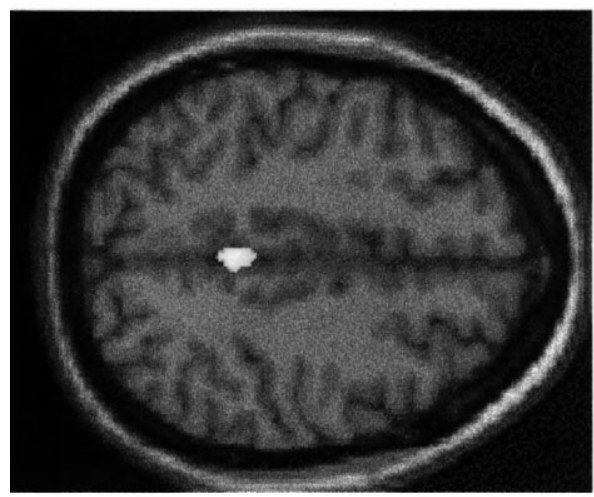

coronal
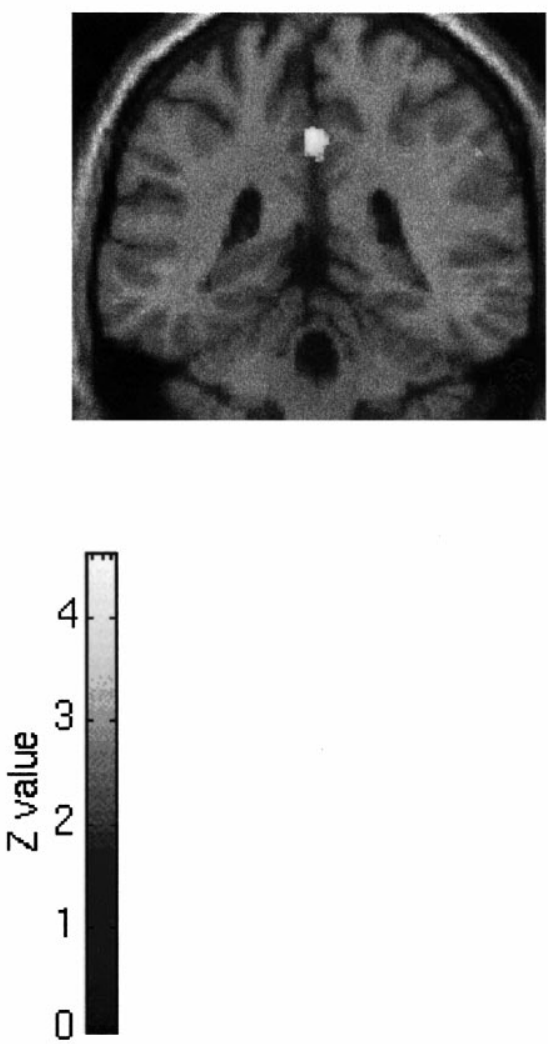

Fig. 3. A statistical parametric map (SPM) showing a region of posterior cingulate cortex where neural responses positively covaried with subjects' self-report of 'urge to use' heroin $(P<0.001$, uncorrected). The activation is displayed on orthogonal slices of a canonical MRI centred on the maximally activated voxel $(x=0, y=38, z=44)$. An uncorrected $P$ value of less than or equal to 0.001 was used as the threshold for the displayed activation.

Table 3

Stereotactic co-ordinates of brain activation areas correlating with cue evoked clinical responses

\begin{tabular}{|c|c|c|c|c|c|c|c|c|}
\hline Symptom/sign & Region/Brodmann Area (BA) & Hemisphere & Activation & $x$ & $y$ & $z$ & $Z$ score & $P$ value \\
\hline \multirow[t]{3}{*}{ Happy VAS } & Frontal cortex/BA 9 & $\mathrm{~L}$ & Increased & -44 & 18 & 36 & 5.44 & $0.001^{\mathrm{a}}$ \\
\hline & Insula & $\mathrm{R}$ & Increased & 52 & 12 & 4 & 3.62 & $<0.001^{\mathrm{b}}$ \\
\hline & Pre-cuneus & $\mathrm{R}$ & Increased & 2 & -54 & 46 & 3.09 & $0.001^{\mathrm{b}}$ \\
\hline \multirow[t]{2}{*}{ Tense VAS } & Insula & $\mathrm{R}$ & Increased & 36 & 10 & -2 & 4.70 & $<0.05^{\mathrm{a}}$ \\
\hline & Cerebellum & $\mathrm{R}$ & Increased & 0 & -48 & -4 & 4.82 & $<0.05^{\mathrm{a}}$ \\
\hline & & $\mathrm{R}$ & Increased & 16 & -14 & -16 & 3.30 & $<0.001^{\mathrm{b}}$ \\
\hline \multirow{2}{*}{ Pulse } & Insula & $\mathrm{R}$ & Increased & 40 & 0 & 4 & 4.53 & $<0.05^{\mathrm{a}}$ \\
\hline & Midbrain & $\mathrm{L}$ & Decreased & -2 & -22 & -10 & 3.68 & $<0.001^{\mathrm{b}}$ \\
\hline
\end{tabular}

${ }^{a} P$ corrected for whole brain comparison.

${ }^{\mathrm{b}} P$ not significant.

\section{Discussion}

\subsection{Self-report and physiological data}

During the experiment the reported urge to use heroin was influenced by the salient video and this effect was most marked on the first occasion when subjects viewed the videos. Possible factors influencing the later responses include direct drug effect in the non-placebo sessions, and habituation effects. An effect of drug is suggested since there was no significant effect of the salient video when the second neutral-salient video pair was viewed in the drug session. However, presence or absence of the drug heroin itself was not 
associated with any independent effect on reported urge to use; neither was it a component of any interaction. Possible effects of habituation to the salient stimulus cannot be ruled out. Exposure to this set of conditioned cues, therefore, was strongly associated with a reported urge to use heroin, which may have attenuated over the course of each session due to within session habituation. Injection of heroin was associated with reports by subjects that they felt high and this was most marked immediately after the injection. It is consistent with clinical descriptions of the 'rush' of heroin, and laboratory recording of effects of heroin administration that the effect of intra-venous heroin would be strongest immediately after the injection, remaining clear but becoming less strong over the next few minutes (Strang

\section{transverse}

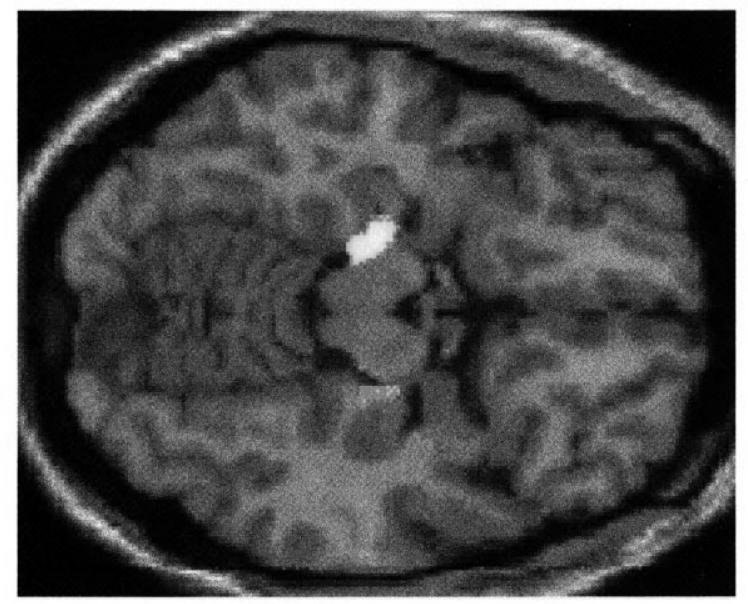

\section{coronal}

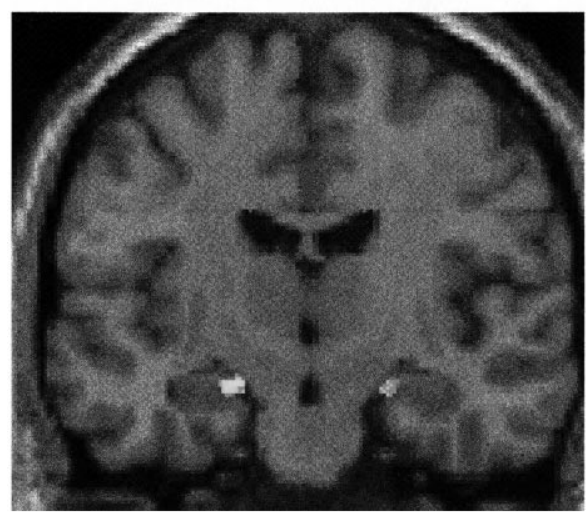

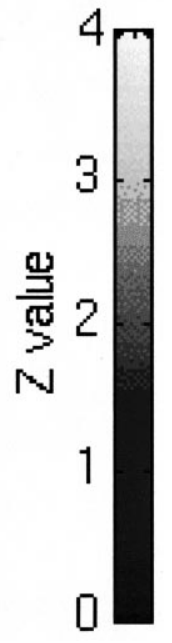

Fig. 4. A statistical parametric map (SPM) showing bilateral regions of the hippocampal cortex where neural responses positively covaried with subjects' self-report of feeling 'high' $(P<0.001$, uncorrected $)$. The activation is displayed on transverse $(z=-16)$ and coronal $(y=14)$ slices of a canonical MRI. An uncorrected $P$ value of less than or equal to 0.01 was used as the threshold for the displayed activation. et al., 1998). Figure 2 and the ANOVA results are consistent with this description. Possible explanations for the gradual decrease in pulse rate during the experiment are a gradual accommodation to the stress of the procedure, though it was not mirrorred by changes in self-reported anxiety, and a gradual effect of heroin, since the effect was most marked in the heroin compared with the placebo condition.

\subsection{Neuroimaging data}

Models of conditioning and reward implicate neural systems including the mesolimbic dopamine system, limbic and pre-frontal regions (Altman et al., 1996). This study demonstrates strong correlations between activity in the inferior frontal and orbitofrontal cortex, and the subjective self-report of a measure of the urge to use heroin, in injecting heroin dependent patients. Thus, the target regions of the mesolimbic dopamine system are implicated in the expression of an urge to use heroin in response to heroin-related cues and in the effects of the drug itself in human heroin addicts. The orbitofrontal context is implicated in the mediation of reward-related behaviour and is a target region of the mesolimbic dopamine system. Parallels have been drawn between drug use and other compulsive behaviours, and the orbitofrontal cortex has been demonstrated as relevant to the pathology of obsessive compulsive disorder, where subjective urge is a central feature (McGuire et al., 1994; McGuire, 1995). Frontal cortex activation extends to bilateral ventral prefrontal activation, an area which, in association with orbitoprefrontal cortex, has an important role in emotion (Yamamoto et al., 1984; Baker et al., 1997).

The reported subjective urge to use heroin was also associated with highly significant activation in the right posterior cingulate region bordering the pre-cuneus. Activation of the right pre-cuneus also correlated with self-report of feeling happy. This region is strongly implicated in episodic memory retrieval (i.e. conscious recall of past experiences), where a specific association is reported with mental imagery (Shallice et al., 1994). In the present experiment, subjects were required to watch videos, which were likely to include cues that were highly salient to their history of past drug use. Knowledge about conditioned responses to drug related cues predicts that feelings and desires would be evoked by such cues, as is clear in the self report data. Mental images of real life past drug use are also likely to be evoked by the drug-related cues, which might mediate the observed conditioned responses. Thus it is possible that visual memories evoked by salient drug-related cues are reprocessed in this region and serve as conditioned stimuli that provoke conditioned responses. Thus, we argue that the association between posterior cingulate cortex activity and urge to use reflects the 
mediatory influence of associated mental imagery as conditioned stimuli.

The urge to use heroin was associated with an increased neural response in the left insula. The insula is implicated in processing and recall of the emotional relevance of stimuli and in anxiety states (Casey et al., 1995; Fink et al., 1996; Phillips et al., 1997) and has projections to anterior cingulate, perirhinal, entorhinal and periamygdaloid cortices as well as to several amygdaloid nuclei (Mesulam and Mufson, 1982). In this experiment the insula also showed increased cerebral blood flow which correlated with self report of feeling happy, feeling anxious and pulse rate. Expression of an urge to use heroin is plausibly associated with anxiety, for several reasons. There may be a component of withdrawal, conditioned or otherwise, there may be conflict between urge to use and intention to detoxify from heroin, and there may be anxiety related to uncertainty about the availability of heroin. The insula is known to have a role in anticipatory anxiety and in somatosensory control including pulse rate (Chuya et al., 1999). We have proposed that a general function of the insula relates to its role in remapping the altered somatosensory state that ensues with emotional arousal, which will of course be strongly associated with anxiety, feelings of happiness and increased pulse rate.

Decreased cerebral activation was seen bilaterally in the occipital cortex, which correlated with self report of urge to use heroin. Activation of visual areas in response to salient cues can occur (Morris et al., 1998), but the relevance of decreased flow in association with self-reported urge to use is not immediately clear. One possibility is that it reflects a modulation of visual regions consequent upon a shift of attention from an external to an internal environment associated with a compelling urge to use. It is also possible that this result reflects a relative deactivation consequent on increased activation elsewhere in the brain.

The pattern of association with 'urge to use' is distinct from that which we previously reported due to salient video exposure or the effect of heroin (Sell et al., 1999). We measured the neural activity, which correlates with reported urge to use heroin in settings where subjects were exposed to heroin, placebo, a salient drug-related or neutral video. Subjects report significantly more urge to use heroin when watching the salient than the neutral video and significantly more heroin-like effects when given heroin than placebo. Note that the measurement of urge to use drugs and of drug-like effects is along a continuum and the results reported reflect brain areas where activity correlates with self-report irrespective of experimental context. Had urge to use been determined solely by effects of conditioned craving, we would expect the cerebral blood flow during exposure to the salient video and that, which correlates with urge to use heroin, to be very similar. While our previous report demonstrated that neural activity increased in mid-brain structures the correlation analysis reported here reveals a different response profile. The urge to use drugs, whilst powerfully influenced by salient cues, is also likely to be determined by anticipation of drug effects (outcome expectancy) by knowledge of availability, by the pre-existing recent drug use, i.e. presence or absence of drug in the body already and by other cognitive and emotional factors including mood (Powell et al., 1992; Robbins and Ehrman, 1992). Therefore the variable 'urge to use heroin' in this design is unlikely to be purely a conditioned response to the salient video, but is likely to reflect the variable influence of the factors described above.

A striking finding in this experiment was that hippocampal activity correlated with self-report of feeling high, i.e. with euphoriant effects of heroin. The hippocampus has a known role in neural mechanisms of drug addiction, in that morphine induces a conditioned place preference, not only when it is injected either systemically (Mucha et al., 1982), or directly into ventral tegmental area (Wise and Hoffman, 1992) and nucleus accumbens (Van der Kooy et al., 1982), both components of the mesolimbic dopamine system, but also when microinjected into the hippocampus (Corrigall and Linseman, 1988). Hence it is suggested that the hippocampus has a complementary role with the amygdala in the formation of stimulus-reinforcer associations (Selden et al., 1991), and it may also increase operant responding for drugs (Burns et al., 1993). More speculatively, it has been suggested that a more general role of the hippocampus in learning and memory may contribute to drug addiction. The functions of the hippocampus may thus extend beyond learning about stimulus-stimulus associations ('explicit memory') but also involve learning the relationship between external cues and internal states, which could subsume the affective effects of heroin (White, 1996). As indicated by our previous report, this effect is distinct from the direct effects of heroin per se, since increased neural response to heroin did not include the hippocampus. We therefore suggest that our results support a role for the hippocampus in linking internal cues to specific memories of heroin-induced states, a process necessary for self-reporting the extent to which an addict currently feels high.

It might be predicted that self-report of feeling happy would show some overlap with self report of feeling high. The relationship between this variable and activity in pre-cuneus and insula has been discussed. However, there was a significant correlation with increased blood flow in dorsolateral prefrontal cortex, an area where there is decreased activity in depressed mood states (Bench et al., 1992). The positive correlation 
between feeling happy and the nucleus accumbens is striking, given its pre-eminent role in reward-related behaviour.

In summary, this study has enabled us to investigate patterns of brain activity during reported urge to use heroin and during self-reported heroin related states, both in the presence and in the absence of the drug itself. This relates to the real life situation of a dependent addict whose urges to use heroin are sometimes frustrated but often gratified. Our findings have relevance to questions regarding neural mechanisms of reward in humans. The findings here also have more general relevance in that they speak to issues regarding the functional role of critical brain structures in human cognition and subjective states. In this regard the data implicate a wider role for the human hippocampus beyond episodic memories while also indicating that theories of drug craving must include the significance of imagery of past drug use as a mediating component in drug-related behaviour.

\section{Acknowledgements}

We wish to thank all the patients who participated in this study and Lorraine Wilson and the nursing staff of Wickham Park House, Bethlem Royal Hospital for invaluable help in recruitment and patient care. This research was partly funded by the Wellcome Trust. RSJF, KJF, JM and RJD are supported by the Wellcome Trust.

\section{References}

Altman, J., Everitt, B.J., Glautier, S., Markou, A., Nutt, D., Oretti, R., Phillips, G.D., Robbins, T.W., 1996. The biological social and clinical bases of drug addiction: commentary and debate. Psychopharmacology 125, 285-345.

Baker, S.C., Frith, C.D., Dolan, R.J., 1997. The interaction between mood and cognitive function studied with PET. Psychol. Med. 27, 565-578.

Bench, C.J., Friston, K.J., Brown, R.G., Scott, L.C., Frackowiak, R.S.J., Dolan, R.J., 1992. The anatomy of melancholia-focal abnormalities of cerebral blood flow in major depression. Psychol. Med. 22, 607-615.

Berger, S.P., Hall, S., Mickalian, J.D., Reid, M.S., Crawford, C.A., Delucchi, K., Carr, K., 1996. Haloperidol antagonism of cue elicited cocaine craving. Lancet 347, 504-508.

Burns, L., Robbins, T.W., Everitt, B.J., 1993. Differential effects of excitotoxic lesions of the baso-lateral amygdala, ventral subiculum and medial pre-frontal cortex on responding with conditioned reinforcement and locomotor activity potential by intra-accumbens infusions of D-amphetamine. Behav. Brain Res. 55, 167-183.

Cador, M., Robbins, T.W., Everitt, B.J., 1989. Involvement of the amygdala in stimulus reward associations: interaction with the ventral striatum. Neuroscience 30 (1), 77-86.

Casey, K.L., Minoshima, S., Morrow, T.J., Koeppe, R.A., Frey, K.A., 1995. Imaging the brain in pain-potentials, limitations and implications. Adv. Pain. Res. Ther. 22, 201-211.
Childress, A.R., Mclellan, A.T., O'Brien, C.P. (1986a). Role of conditioning factors in the development of drug dependence, Psychiatr. Clin. North Am. 9, 413-425.

Childress, A.R., Mclellan, A.T., O’Brien, C.P., 1986b. Abstinent opiate abusers exhibit conditioned craving, conditioned withdrawal and reductions in both through extinction. Br. J. Addict. 81, 655-660.

Childress, A.R., McLellan, A.T., O’Brien, C.P., 1993. Conditioned responses in a methadone population. J. Subst. Abuse Treat. 3, $173-179$.

Chuya, P., Krams, M., Passingham, R., Dolan, R.J. (1999). A functional anatomy of anticipatory anxiety. Neuroimage 9, 563571.

Corrigall, W.A., Linseman, M.A., 1988. Conditioned place preference produced by intra-hippocampal morphine. Pharmacol. Biochem. Behav. 30, 787-789.

Davis, W.M., Smith, S.G., 1976. Role of conditioned reinforcers in the initiation, maintenance and extinction of drug seeking behaviour. Pav. J. Biol. Sci. 11, 222-236.

DiChiara, G., North, R.A., 1992. Neurobiology of opiate abuse. Trends Pharmacol. Sci. 13, 185-193.

DiChiara, G., 1995. The role of dopamine in drug abuse viewed from the perspective of its role in motivation. Drug Alcohol Depend. 38, 95-137.

Fink, G.R., Markowitsch, H.J., Reinkemeir, M., Bruckbauer, T., Kesler, J., Heiss, W.D., 1996. Cerebral representation of ones own past-neural networks involved in autobiographical memory. J. Neurosci. 16, 4275-4282.

Fontana, D.J., Post, R.M., Pert, A., 1993. Conditioned increases in mesolimbic dopamine overflow by stimuli associated with cocaine. Brain Res. 629, 31-39.

Friston, K.J., Frith, C.D., Liddle, P.F., Frackowiak, R.S.J., 1991. Comparing functional (PET) images; The assessment of significant change. J. Cereb. Blood Flow Metab. 11, 690-699.

Friston, K.J., Holmes, A.P., Worsley, K., Poline, J.B., Frith, C.D., Frackowiak, R.S.J., 1995a. Statistical parametric maps in functional imaging: a general linear approach. Hum. Brain Map. 2, 189-210.

Friston, K.J., Ashburner, J., Frith, C.D., Poline, J.B., Heather, J.D., Frackowiak, R.S.J., 1995b. Spatial registration and normalization of images. Hum. Brain Map. 2, 165-189.

Kim, H.S., Iyengar, S., Wood, P.L., 1986. Opiate actions on mesocortical dopamine metabolism in the rat. Life Sci. 39, 2033-2036.

Koob, G.F., 1992. Neural mechanisms of drug reinforcement. Ann. New York Acad. Sci. 654, 171-191.

McGuire, P.K., Bench, C., Marks, I., Frith, C.D., Dolan, R.J., Frackowiak, R.S.J., 1994. Functional anatomy of obsessive-compulsive phenomena. Br. J. Psych. 164, 459-468.

McGuire, P.K., 1995. The brain in obsessive-compulsive disorder. J. Neurol. Neurosurg. Psychiatry 59, 457-460.

Mesulam, M.M., Mufson, E.J., 1982. Insula and the old world monkey. 3. Efferent cortical output and comments on function. J. Comp. Neurol. 212, 38-52.

Morris, J.S., Friston, K.J., Beuchal, C., Frith, C.D., Young, A.W., Calder, A.J., Dolan, R.J., 1998. A neuromodulatory role for the human amygdala in processing facial expressions. Brain 121, 47-57.

Mucha, R.F., Van der Kooy, D., O’Shaunessy, M., Buchnieks, P., 1982. Drug reinforcement studied by the use of place conditioning in rat. Brain Res. 243, 91-105.

Phillips, A.G, Pfaus, J.G., Blaha, C.D., 1991. Dopamine and motivated behaviour: insights provided by in vivo analyses. In: Willner, P., Scheel-Kruger, J. (Eds.), The Mesolimbic Dopamine System: From Motivation to Action. Wiley, London, pp. 199224.

Phillips, M.L., Young, A.W., Senior, C., Brammer, M., Andrew, C., Caler, A.J., Bullmore, E.T., Perrett, D.I., Rowland, D., Williams, 
S.C.R., et al., 1997. A specific neural substrate for perceiving facial expressions of disgust. Nature 389, 495-498.

Pickens, R.W., Johanson, C.E., 1992. Craving: consensus of status and agenda for future research. Drug Alcohol Depend. 80, $127-$ 131.

Powell, J., Bradley, B., Gray, J.A., 1992. Classical conditioning and cognitive determinants of subjective craving for opiates: An investigation of their relative contributions. Br. J. Addict. 87, 11331144.

Robbins, T.W., Cador, M., Taylor, J.R., Everitt, B.J., 1989. Limbic striatal interactions in reward related processes. Neurosci. Biobehav. Rev. 13, 155-162.

Robbins, S.J., Ehrman, R.N., 1992. Designing studies of drug conditioning in humans. Psychopharmacology 106, 143-153.

Robbins, T.W., Everitt, B.J., 1996. Neurobehavioral mechanisms of reward and motivation. Curr. Opin. Neurobiol. 6 (2), 228-236.

Schultz, W., Dayan, P., Read Montague, P., 1997. A neural substrate of prediction and reward. Science 275, 1593-1598.

Schulteis, G., Koob, G., 1994. Dark Side of drug dependence. Nature 371 (8 Sep), 108-109.

Selden, N.R.W., Everitt, B.J., Jarrard, L.E., Robbins, T.W., 1991. Complementary roles for the amygdala and hippocampus in aversive conditioning to explicit and contextual cues. Neuroscience 42, 335-350.

Sell, L.A., Cowen, P.J., Robson, P.J., 1995. Ondansetron and opiate craving. A novel pharmacological approach to addiction. Br. J. Psychiatry 166, 511-514.

Sell, L.A., Morris, J., Bearn, J., Frackowiak, R.S.J., Friston, K.J., Dolan, R.J., 1999. Activation of reward circuitry in human opiate addicts. Eur. J. Neurosci. 11, 1042-1048.

Shallice, T., Fletcher, P., Frith, C.D., Grasby, P., Frackowiak, R.S.J., Dolan, R.J., 1994. Brain regions associated with acquisition and retrieval of verbal episodic memory. Nature 368, 633-635.

Solomon, R.L., Corbit, J.D., 1974. An opponent process theory of motivation: I temporal dynamics of affect. Psychol. Rev. 81, $119-145$.
Strang, J., Bearn, J., Farrell, M., Finch, E., Gossop, M., Griffiths, P., Marshall, J., Wolff, K., 1998. Route of drug use and its implications for drug effect, risk of dependence and health consequences. Drug Alcohol Rev. 17, 197-211.

Talairach, J., Tournoux, P. (Eds.), 1988. Co-planer Stereotaxic Atlas of the Human Brain. Springer, New York.

Tiffany, S.T., 1990. A cognitive model of drug urges and drug use behaviour; role of automatic and non-automatic processes. Psychol. Rev. 97, 147-168.

Trusk, T.C., Stein, E.A., 1988. Effect of heroin conditioned auditory stimluli on cerebral functional activity in rats. Pharmacol. Biochem. Behav. 30 (4), 983-993.

Van der Kooy, D., Mucha, R.F., O'Shaunessy, M., Buchnieks, P., 1982. Reinforcing effects of morphine revealed by conditioned place preference. Brain Res. 243, 107-117.

White, N.M., 1996. Addictive drugs as reinforcers: multiple partial actions on memory systems. Addiction 91 (7), 921-950.

Whitelaw, R.B., Markou, A., Robbins, T.W., Everitt, B.J., 1996. Excitotoxic lesions of the basolateral amygdala impair the acquisition of cocaine seeking behaviour under a second order schedule of reinforcement. Psychopharmacol. Berl. 127 (3), 213-224.

Wikler, A., 1948. Recent progress in research on the neurophysiologic basis of morphine addiction. Am. J. Psychiatry 105, 329-338.

Williams, G.V., Rolls, E.T., Leonard, C.M., Stern, C., 1993. Neuronal responses in the ventral striatum of the behaving macaque. Behav. Brain Res. 55 (2), 243-252.

Wise, R.A., Bozarth, M.A., 1987. A psychomotor stimulant theory of addiction. Psychol. Rev. 94, 469-492.

Wise, R.A., 1988. The neurobiology of craving: implications for the understanding and treatment of addiction. J. Abn. Psychol. 97 (2), $118-132$.

Wise, R.A., Hoffman, D.C., 1992. Localization of drug reward mechanisms by intracranial injections. Synapse 10, 247-263.

Wise, R.A., 1996. Neurobiology of addiction. Curr. Opin. Neurobiol. 6, 243-251.

Yamamoto, T., Oomura, Y., Nishino, H., 1984. Monkey orbitofrontal neuron activity during emotional and feeding behaviours. Brain Res. Bull. 12, 441-443. 